Boise State University

ScholarWorks

11-4-2016

Stakeholder Values, Land Use, and Ecosystem Services Trade-Offs

Jenna Narducci

Boise State University

Jodi Brandt

Boise State University

Antonio Castro

Idaho State University 


\section{Stakeholder Values, Land Use, and Ecosystem Services Trade-offs}

Jenna Narducci, Human-Environment Systems Center, BSU

Jodi Brandt, Human-Environment Systems Center, BSU

Antonio Castro, Social-Ecological Research Lab, ISU

\section{METHODS}

- Consulted experts at Boise State University and Idaho State University to determine applicable ecosystem services to study areas

- Conducted over 900 face-to-face surveys in study areas; data collected included:

- Ecosystem Services perceptions and preferences

- Opinions on how land use and climate may affect different ecosystem services

- Demographic data and environmental attitudes

\section{NEXT STEPS}

- Interview key policy informants to establish policy scenarios

- Model how different policy scenarios will impact land use change and trade-offs between ecosystem services

- Quantify and map biophysical supply of ecosystem services

- Explore trade-offs and synergies between ecosystem services supply and demand

\section{REFERENCES \& ACKNOWLEDGEMENTS}

Thank you respondents in the PV and TV and to our team of collaborators: Jodi Brandt, Antonio Castro, Dainee Gibson, \& Sara Bernardini. Thank you to our undergraduate research associates: Melissa Valencia, Xochitl Sanchez, \& Daniel Bakyono, Sandra Carrillo, Jessica Hamway, \& Estela Okech

Contact: jennanarducci@boisestate.edu

Literature Cited

R.D. Swetnama, B. Fisherb, c, B.P. Mbilinyid, P.K.T. Munishid, S. Willcocke T. Rickettsf, S. Mwakalilag, A.Balmforda, N.D. Burgessa, f, A.R. Marshallh, S.L. Lewre. Joun

2010.09.00

Complexity (2010) 7:260-272.

http://dx.doi.org/10.1016/j.ecocom.2009.10.00

\section{BACKGROUND}

Communities are increasingly concerned about how population growth and climate change impact human well-being. ${ }^{1}$ Along with these large-scale issues, researchers and managers recognize the need to address diverse stakeholder values in order to implement successful policies. ${ }^{2}$

Our project determines what stakeholders value most about their surrounding environment, and trade-offs between ecosystem services that will occur based on different policy scenarios.

Our desire is to produce data that is applicable to urban planners and land managers in shaping the best alternatives for their community.

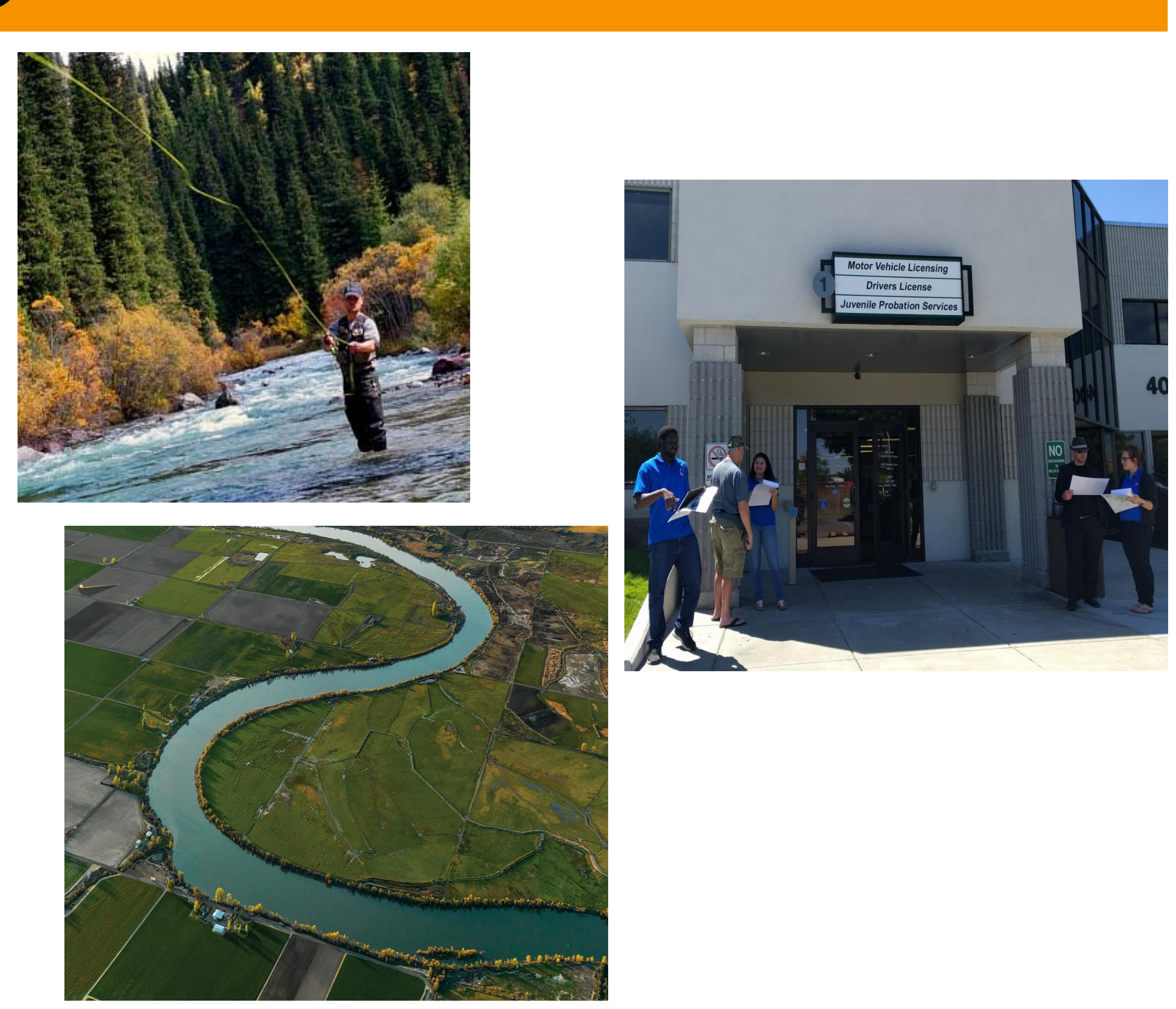

\section{PRELIMINARY RESULTS}

\section{Treasure Valley}

a. Urban development b. Agricultural land
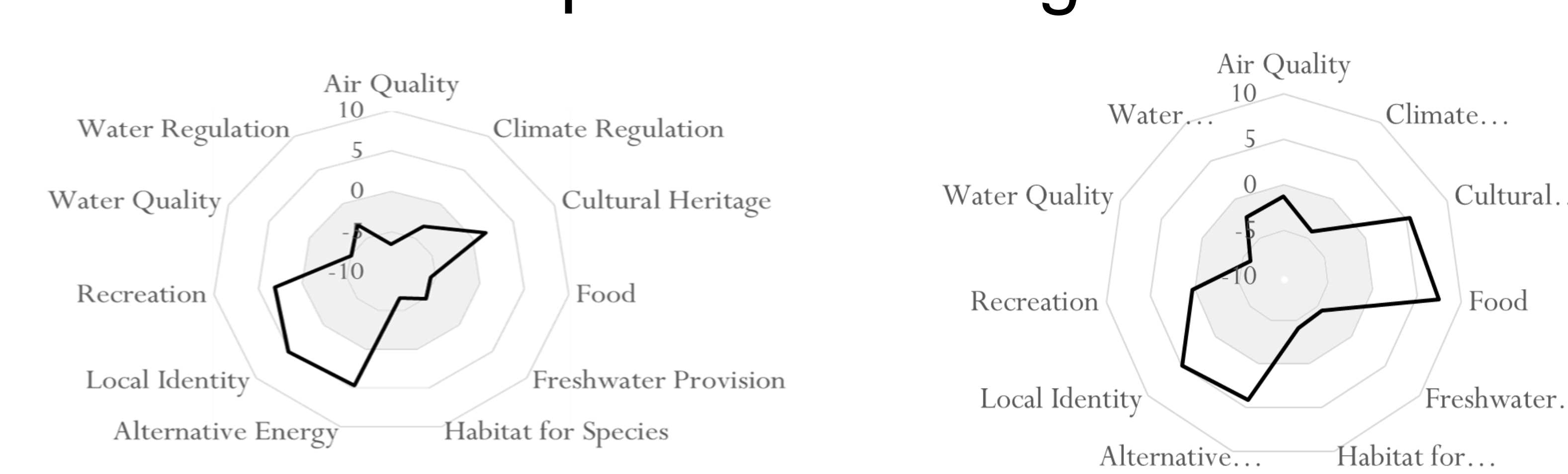

c. Rangeland

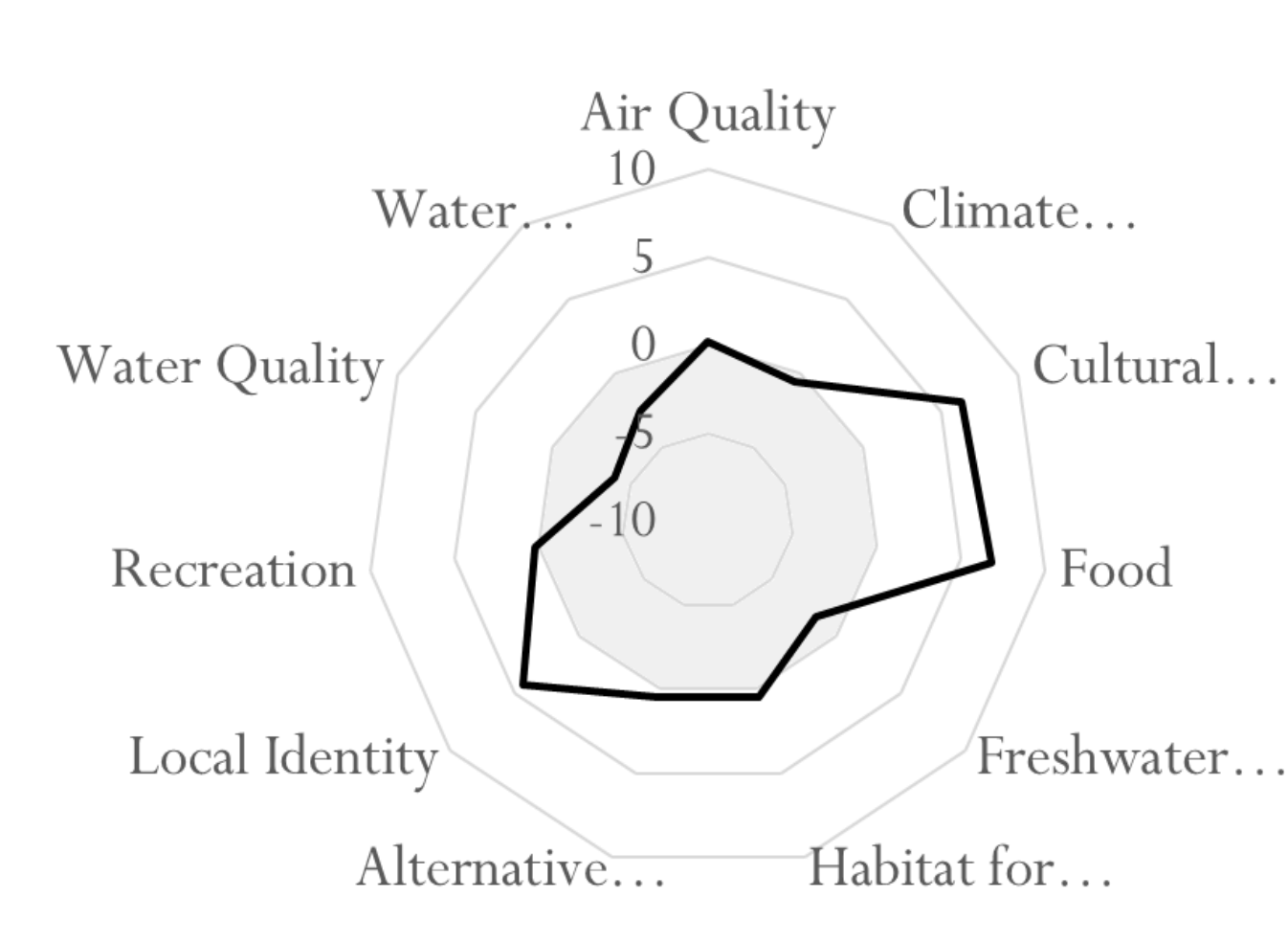

d. Urban \& natural forest

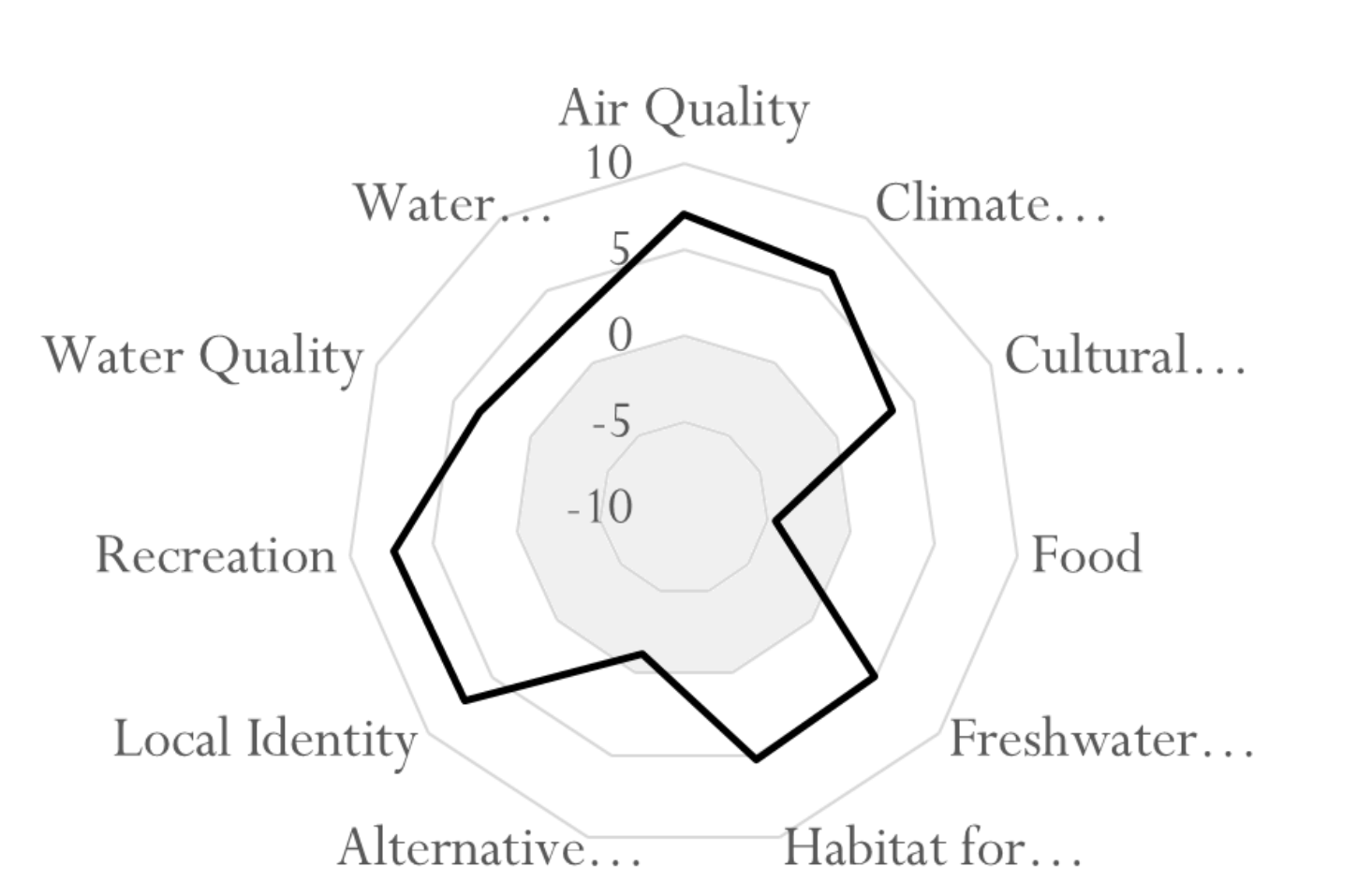

\section{Portneuf Valley}

a. Urban development

b. Agricultural land
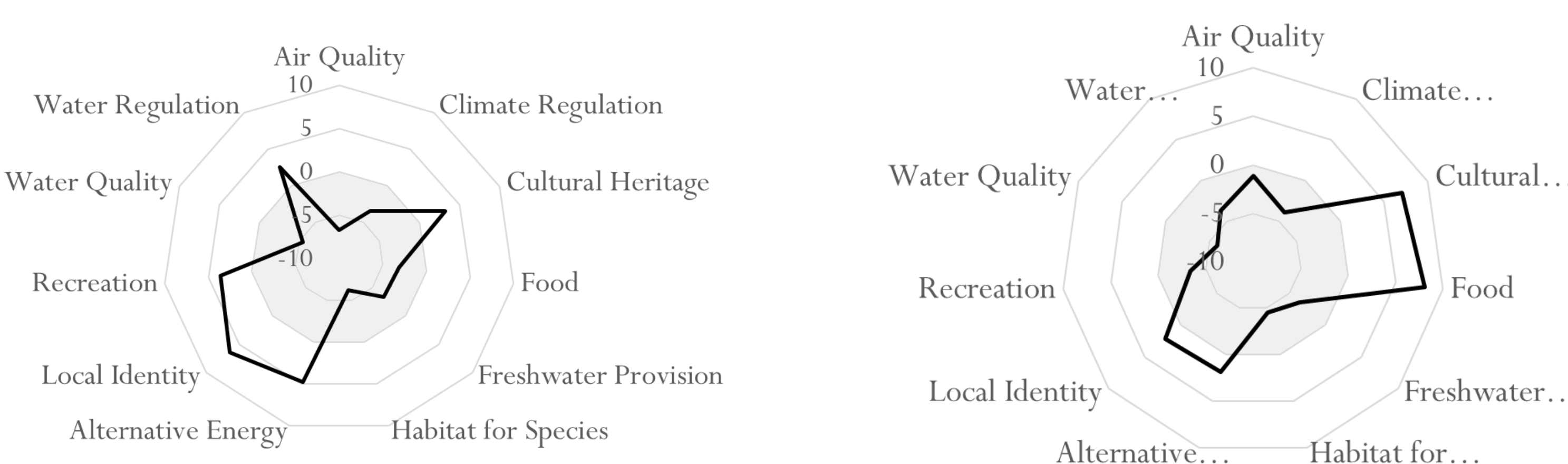

c. Rangeland

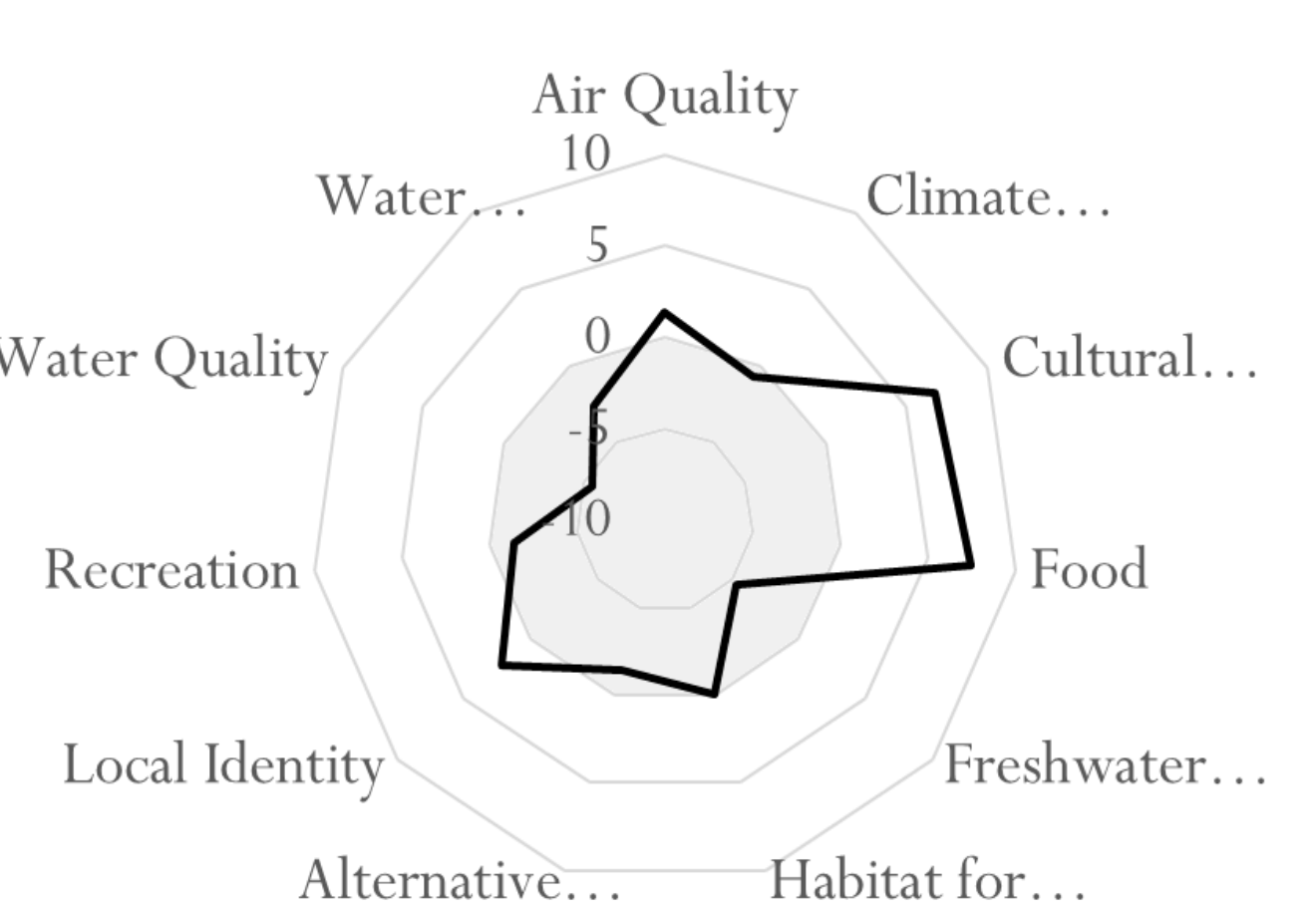

d. Urban \& natural forest

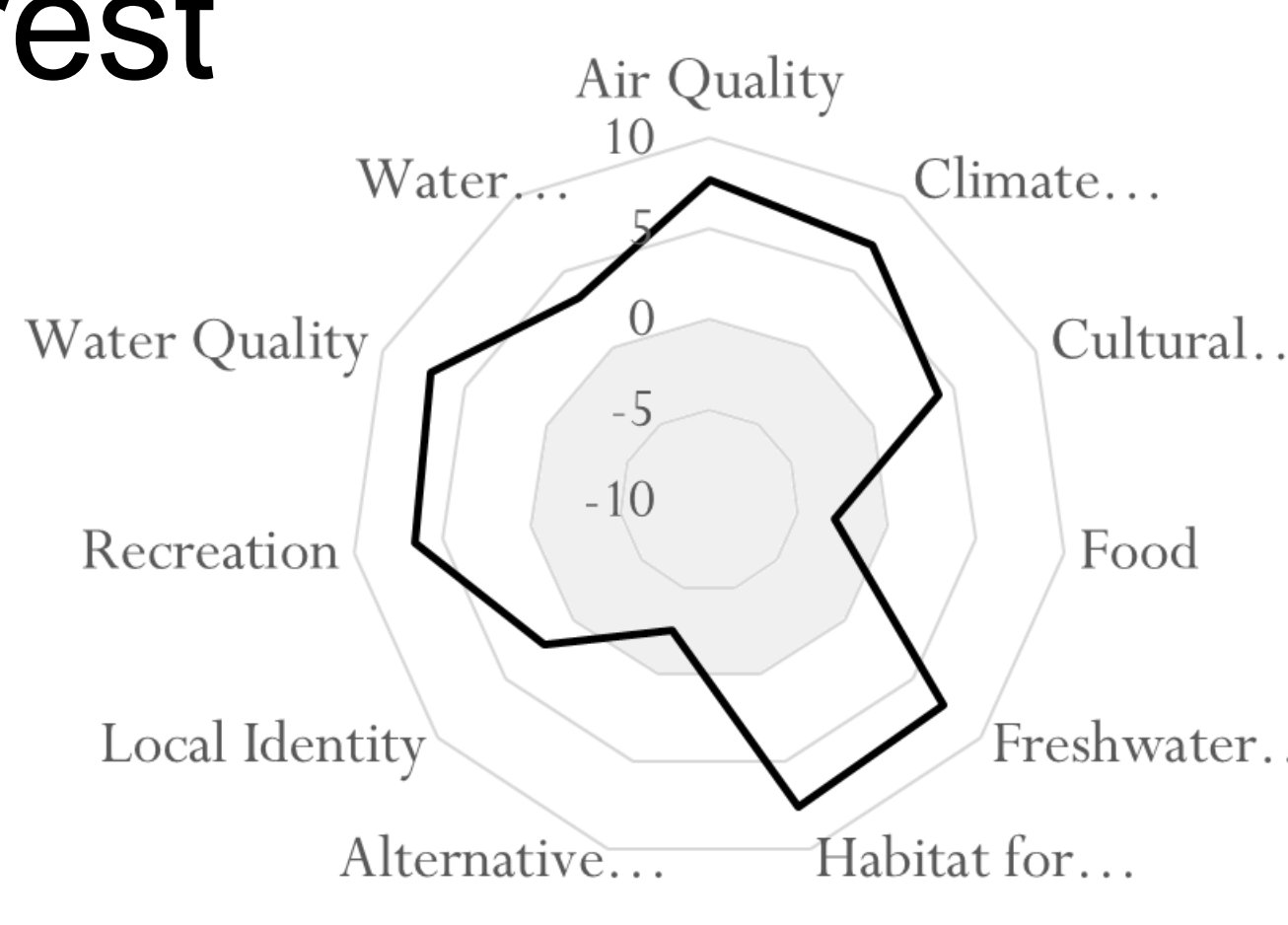

Perceived tradeoffs between Ecosystem Services under different land uses. The gray area (negative axis) in the spider diagram represents a relative negative impact, as perceived by the respondents. The white area (positive axis) in spider diagrams represents a relative positive impact. 